\title{
Study on the effectiveness of pesticides against cowpea aphid (Aphis craccivora) Koch
}

\author{
V. GOWTHAM*, N. DILIPSUNDAR, K. BALAJI AND S. KARTHIKEYAN ${ }^{1}$ \\ College of Agricultural Technology, THENI (T.N.) INDIA \\ ${ }^{1}$ Department of Agricultural Entomology, Tamil Nadu Agricultural University, COIMBATORE (T.N.) INDIA
}

\section{ARITCLE INFO}

Received : 01.02 .2016

Revised : 16.02 .2016

Accepted : 01.03 .2016

\section{KEY WORDS :}

Chemical pesticide, Efficiency,

Cowpea, Aphid

*Corresponding author:

Email: gowtham.v.agri@gmail.com

\begin{abstract}
Considering the importance of safe food, avoiding of excess pesticide application and pesticide pollution the present study was conducted. In this experiment totally four pesticides were tested against cowpea aphid Aphis craccivora under pot culture experiment at College of Agricultural Technology, Theni. Among the four acetamprid $20 \mathrm{SP}(0.125 \mathrm{~g} / \mathrm{ml})$ proved highly effective against Aphis craccivora compared to the rest of the pesticides with mortality of 98.75 per cent. In case of dosage wise acetamprid $20 \mathrm{SL}(0.125 \mathrm{~g} / \mathrm{ml})$ and imidacloprid $17.8 \mathrm{SL}(0.25 \mathrm{ml} / \mathrm{l})$ proved to be highly effective with mortality percentage of 98.33 and 86.66 , respectively. Thus, it is concluded that all the studied pesticides, Acetamprid proved effective to control the cowpea aphids.
\end{abstract}

How to view point the article : Gowtham, V., Dilipsundar, N., Balaji, K. and Karthikeyan, S. (2016). Study on the effectiveness of pesticides against cowpea aphid (Aphis craccivora) Koch. Internat. J. Plant Protec., 9(1) : 146-149. 